\title{
PREHOSPITAL CONTINUOUS POSITIVE AIRWAY PRESSURE FOR ACUTE RESPIRATORY FAILURE: A SYSTEMATIC REVIEW AND META-ANALYSIS
}

\section{ABSTRACT}

\section{INTRODUCTION}

Acute respiratory failure (ARF) is a common problem presenting to emergency medical services and is associated with significant morbidity, mortality and health care costs. Continuous positive airway pressure (CPAP) is an integral part of the hospital treatment of acute respiratory failure, predominantly due to congestive heart failure. Intuitively, better patient outcomes may be achieved when CPAP is applied early in the pre-hospital setting but there are few outcome studies to validate its use in this setting.

\section{AIM}

This systematic review and meta-analysis aimed to examine the effectiveness CPAP in the pre-hospital setting for patients with ARF.

\section{METHODS}

A literature review of bibliographic databases and secondary sources was conducted and potential papers assessed by two independent reviewers. Included studies were those that compared CPAP therapy (and usual care) to no CPAP for ARF in the prehospital setting. Studies of other methods of non-invasive ventilation were not included. Methodological quality was assessed using guidelines from the Cochrane Collaboration. Outcomes included the number of intubations, mortality, physiological parameters and dyspnoea score. Forrest plots were constructed to estimate the pooled effect of CPAP on outcomes.

\section{RESULTS}

Five studies (1,002 patients) met the selection criteria - three randomised control trials (RCTs), a non-randomised comparative study and a retrospective comparative study using chart review. Forty-seven percent of patients were allocated to the CPAP group. Baseline characteristics were similar between groups. The pooled estimates demonstrated significantly fewer intubations (OR 0.31, 95\% CI 0.19-0.51) and lower mortality (OR 0.41, 95\% CI 0.190.87) in the CPAP group.

\section{CONCLUSION}

The studies included in this review showed a reduction in the number of intubations and mortality in patients with ARF who received CPAP in the pre-hospital setting. The results may not be applicable to other health care contexts because of the inherent differences in the 
organisation and staffing of the EMS. Information from large RCTs on the efficacy of CPAP initiated early in the pre-hospital setting is critical to establishing the evidence base underpinning this therapy prior to ambulance services incorporating CPAP as routine clinical practice.

\section{INTRODUCTION}

Acute respiratory failure (ARF), defined by the presence of hyoxaemia or hypercapnia, is a common problem presenting to emergency medical services (EMS). ARF is most commonly caused by diseases of the cardiac (e.g. left ventricular failure, pulmonary embolus) or respiratory system (e.g. chronic obstructive pulmonary disease [COPD], asthma, pneumonia). Identifying the precise cause of ARF in the pre-hospital setting is challenging: the time window for assessment is limited, it is not possible to obtain a chest x-ray or other diagnostic imaging and environmental considerations (avoiding exposing the patient, noise) make clinical examination difficult.

The most common cause of acute respiratory failure is left ventricular failure causing acute cardiogenic pulmonary oedema (ACPO), a potentially life-threatening medical emergency that is associated with significant morbidity, mortality and health care costs. ${ }^{1}$ Other causes of acute pulmonary oedema (APO) are cardiac (includes myocardial ischaemia, hypertension, arrhythmias) and non-cardiac (includes drugs, poisoning). Non-cardiogenic pulmonary oedema is often evident from the patient history surrounding the acute event and is due primarily to a disruption in the alveolar-capillary membrane from an insult (e.g. sepsis, trauma, drugs). ${ }^{2}$ While they have distinct causes, acute cardiogenic and non-cardiogenic pulmonary oedema have similar clinical manifestations. ${ }^{3}$ Furthermore, patients with COPD often present with ACPO due to coexisting cardiac disease and it may be difficult to differentiate between them ${ }^{2}$ especially in the pre-hospital emergency setting. However, it is important to understand the cause of APO because it has important treatment implications. Patients with cardiogenic pulmonary oedema typically are treated with preload and afterload reduction using drugs such as nitrates. Patients with non-cardiogenic pulmonary oedema require support of oxygenation and ventilation and treatment of the underlying cause. ${ }^{3}$

Continuous positive airway pressure (CPAP) is an integral part of the hospital treatment of APO and provides beneficial effects on respiratory and cardiac function. ${ }^{4-6}$ This non-invasive 
medical therapy maintains positive airway pressure during spontaneous ventilation throughout the whole respiratory cycle, reducing dyspnoea and the work of breathing. Several reports that describe CPAP, ${ }^{7-12}$ applied by face or nasal mask, improves gas exchange, reduces the need for endotracheal intubation (and the potential complications of mechanical ventilation), ${ }^{13}$ and decrease length of stay (LOS) in the intensive care unit (ICU), coronary care, emergency department (ED) and hospital. CPAP is most beneficial in patients with APCO, but patients with other causes of acute respiratory failure, e.g. acute exacerbations of COPD also benefit. ${ }^{14}$ Intuitively, better patient outcomes may be achieved when CPAP is applied early in the pre-hospital setting, but outcome studies in the pre-hospital setting are required to validate its use. ${ }^{14,15}$ This information is critical to establishing the evidence base underpinning this therapy prior to EMS incorporating pre-hospital CPAP as routine clinical practice.

\section{METHOD}

\section{Aims}

We conducted a systematic review and meta-analysis of the evidence of the clinical efficacy of pre-hospital administration of CPAP in patients with acute respiratory failure.

\section{Search strategy}

To identify studies eligible for review, computerized searches of bibliographic databases were performed (author TW): MEDLINE (1980-2012), EMBASE (1980-2012), CINAHL (1982-2012) and the Cochrane Library (2004-2012). Terms were mapped to the appropriate MeSH/EMTREE subject headings and “exploded”: (1) [“acute pulmonary oedema” OR “pulmonary oedema” OR “acute heart failure” OR ‘acute respiratory failure”] AND [“continuous positive airway pressure”] (2) [“continuous positive airway pressure”] AND [“ambulance” OR “emergency medical services” OR “pre-hospital care” OR mobile health units ”OR “paramedic”]. Reference lists of relevant review articles and journals were handsearched for relevant papers.

Potential studies were limited to studies conducted within the prehospital setting that compared patients with acute respiratory failure who received CPAP and usual care (CPAP group) to those receiving usual care (non-CPAP group) transported to hospital by ambulance. We did not include studies of neonates. Studies that did not specifically compare patients 
with acute respiratory failure, ${ }^{16,17,18,19}$ did not compare the CPAP group with a non-CPAP group, ${ }^{20,21}$ or those that included patients who received bilevel positive airway/pressure support ventilation ${ }^{22-27}$ were excluded. Outcomes included changes in physiological values (respiratory rate, oxygen saturation $\left[\mathrm{SpO}_{2}\right.$ or $\left.\mathrm{SaO}_{2}\right]$, intubation, mortality and intensive care unit (ICU) or hospital length of stay (LOS). Papers were included if they were published in English. Articles had to be published in peer-reviewed journals but those published only in abstract form were excluded. No time limits on journal publication date were set. If reports described overlapping study populations, we retained the most recent or complete publication.

\section{Study selection}

Studies identified during the literature search were assessed for relevance to the review based on the information contained in the title, abstract and subject descriptor/MeSH heading (authors TW and JF). Full text articles were obtained if, after reviewing the abstract, the study was considered relevant or if the title and abstract were inconclusive. All citations selected by either author for abstract review were eligible for selection, and any subsequent disagreement regarding eligibility resolved by consensus.

\section{Data extraction}

Data were extracted by two investigators (authors TW and JF) from studies that met the inclusion criteria. We did not get primary data verified from investigators. The data were collected on a form that included study design, patient characteristics (e.g. age, sex, diagnosis), treatments received, emergency medical services, reported outcomes (mortality, physiological changes, dyspnoea score, length of stay [LOS]), direction (and magnitude) of treatment effect.

\section{Study quality}

Using guidelines from Ryan et al. ${ }^{28}$ and Higgins and Green, ${ }^{29}$ study quality was assessed for risk of bias, adherence to the intention-to-treat principle, completeness to follow-up, heterogeneity, and loss to follow-up. In addition, for non-randomised studies similarity of baseline characteristics was examined. If groups were not reasonably equivalent and this was not adjusted through analysis, the study was excluded from the analysis. 


\section{Assessment of risk of bias in included studies}

Allocation concealment was rated as (a) adequate if the randomisation method would not enable the investigator or participant to know or influence allocation intervention group before an eligible participant was entered in the study; (b) unclear if randomisation stated but no information on the method used is available; (c) inadequate if the method of randomisation used indicated that investigators or participants could influence the intervention group; and (d) randomisation not done. ${ }^{28}$

\section{Adherence to the intention-to-treat principle}

If an intention-to-treat analysis was reported to have been undertaken by the investigators and this was confirmed on study assessment then adherence to the intention-to-treat principle was assumed. ${ }^{28}$ If not reported and lack of intention-to-treat analysis was confirmed on study assessment, e.g. patients who were randomised were not included in the analysis because they did not receive the study intervention, they withdrew from the study or were not included because of protocol violation, it was assumed that there was no adherence to the intention-totreat principle.

\section{Assessment of heterogeneity}

Statistical heterogeneity was assessed using the Higgins $\mathrm{I}^{2}$ test, ${ }^{30}$ which estimates the variability due to heterogeneity rather than chance alone. $\mathrm{I}^{2}$ values less than $25 \%$ are considered low risk, 25 to $50 \%$ moderate risk and values greater than $50 \%$ high risk of heterogeneity. ${ }^{30}$

\section{Sensitivity analysis}

A priori sensitivity analyses were proposed to explore the impact of excluding studies that met the inclusion criteria but not the assessment of study quality on outcomes.

\section{Publication bias}

The intubation rate from the studies were used to construct a funnel plot, to investigate the likelihood of overt publication bias. ${ }^{29}$ The vertical axis indicates the standard error of the log odds ratio and the horizontal axis the logit odds ratio. ${ }^{31}$ In the absence of bias the plot resembles a symmetric inverted funnel, but if there is bias it appearsasymmetric with a gap in the bottom right-hand side of the graph. ${ }^{29}$ 


\section{Data synthesis}

Narrative and tabular summaries of study characteristics, methods and results are presented, guided by the Preferred Reporting Items for Systematic Reviews and Meta-Analyses (PRISMA) statement. ${ }^{32}$ Summary estimates of treatment effect with their associated $95 \%$ confidence intervals (CI) are reported. A protocol was not registered for the systematic review. We pooled dichotomous outcomes (using odds ratio [OR]) using random effects models. Data were analysed using Review Manager (RevMan) version 5.1 software (The Cochrane Collaboration, Oxford, UK) and STATA (Release 12: StataCorp LP, College Station, TX, USA). We considered $\mathrm{P}$ values $<0.05$ to be statistically significant.

\section{RESULTS}

We identified 160 reports of studies. After title and abstract assessment, 95 reports were excluded because it was evident that the publications were not comparative studies or did not include either the target population or the intervention of interest. We retrieved 65 full text reports for further evaluation, and seven were finally included.

INSERT FIGURE 1 HERE

\section{Study characteristics}

There were 14 studies of CPAP used in the pre-hospital setting. ${ }^{14,16-19,22,33-39}$ We did not include six studies of prehospital CPAP ${ }^{16-19,22,33}$ because they did not have a comparison group. The Plaisance et al. ${ }^{20}$ RCT was excluded because it did not compare the CPAP group to a non-CPAP group but instead compared 'early' CPAP to 'late' CPAP. Seven studies ${ }^{14,34-39}$ compared the effect of prehospital CPAP to no CPAP - three randomised controlled trials $(\mathrm{RCTs})^{14,35,36}$, a non-randomised concurrent comparative study, ${ }^{38}$ two before and after studies, ${ }^{37,39}$ and a retrospective review of prehospital charts. ${ }^{34}$ Only one of the studies involved multiple centers. ${ }^{35}$

The studies included in this review (Table 1) were conducted in different healthcare contexts: one was conducted in Canada, ${ }^{14}$ two in France ${ }^{35,36}$ and four in the United States of America (USA). ${ }^{34,37-39}$ In the mobile ICUs in France, physicians are part of the EMS team, but are not routinely used in the USA and Canada. Differences also exist within the same context. For example, Hubble et al. ${ }^{38}$ used two neighbouring EMS counties with different levels of services: one county for the control group and the other for the intervention group. 


\section{Study quality}

None of the studies were blinded, as shown in Table 1, but it would be technically and operationally difficult to blind the paramedics. The three RCTs ${ }^{14,35,36}$ were considered low risk for bias. Hubble et al. ${ }^{38}$ had a moderate risk of bias because it was a well conducted, nonrandomised comparative clinical study. Two studies had a high risk of bias. ${ }^{34,37,39}$ Hastings et al. ${ }^{37}$ described a decrease in the number of intubations from $20 \%$ to $1 \%$ but did not describe the number of patients or the characteristics of the comparator group and was excluded from the outcome analyses. ${ }^{37}$ Warner et al. ${ }^{39}$ conducted a before and after study but did not describe the characteristics of the groups and was also excluded from further analyses. Publication bias is shown in Figure 2.

INSERT TABLE 2 HERE

INSERT FIGURE 2 HERE.

\section{Study participants}

There were 1002 patients enrolled across five studies, ${ }^{14,34-36,38}$ of whom 471 (47\%) were allocated to the CPAP group. The number of patients recruited in each study ranged from 71 to 387 . The average age of participants was 76 years non-CPAP group versus 75 years in the CPAP group (when reported) and the proportion of males was similar (50\% non-CPAP group versus $47 \%$ CPAP group, $\mathrm{p}=0.25$ ). Three studies reported outcomes for patients with severe $\mathrm{CHF}^{34}$ or ACPO. ${ }^{35,36}$ A further study examined outcomes for patients with APO but the majority of patients (76\%) were diagnosed in ED with cardiogenic pulmonary oedema. ${ }^{38}$ Thompson et al. ${ }^{14}$ recruited patients with severe respiratory distress, predominantly CHF, COPD or asthma.

Standard therapy included use of oxygen, nitrates and diuretics (furosemide) although the mode of delivery (oral versus parenteral) varied within and between EMS. The therapies for APO were provided at the discretion of the treating paramedics, ${ }^{34,38}$ or protocol-driven ${ }^{35,36}$ depending on the EMS but some adjunctive therapies were mandatory. ${ }^{35}$ Delivery of CPAP was by facemask. ${ }^{14,35,36,38}$ CPAP was generated by oxygen-driven Venturi devices which deliver high gas flow with adjustable fractional inspired oxygen $\left(\mathrm{FiO}_{2}\right)$ in three studies ${ }^{35,36,38}$ or fixed-flow generator with pre-set FiO2 and no allowance for titration of $\mathrm{FiO}_{2}{ }^{34}$ Four studies set the pressure for CPAP at $10 \mathrm{~cm}^{14,34,36,38}$ and Ducros et al. ${ }^{35}$ initially set the 
pressure for CPAP to $7.5 \mathrm{~cm} \mathrm{H} \mathrm{H}_{2} \mathrm{O}$ for 15 minutes and increased it to $10 \mathrm{~cm} \mathrm{H}_{2} \mathrm{O}$ if tolerated. Only one study ${ }^{35}$ set a target $\mathrm{SpO}_{2}$.

\section{Outcomes}

Outcomes from the five studies included in this systematic review are shown in Table 3. The requirement for intubation overall was reported as a primary or secondary outcome in five studies $^{14,34,36,38,39}$ or included as part of a composite outcome. ${ }^{35}$ Different time points were used to assess intubation rates. The use of CPAP was associated with a $69 \%$ reduction in the number of intubations overall, as shown in Figure 2 (OR 0.31, 95\%CI 0.19-0.51). Similar results were found when the two French studies were excluded (OR 0.30, 95\% CI 0.17$0.53)^{35,36}$ but not significant for pre-hospital intubation only (OR 0.43, 95\% CI 0.181.02). ${ }^{14,34,36}$

\section{INSERT TABLE 3 HERE}

\section{INSERT FIGURE 3}

Composite endpoints were used as the primary outcome in two studies. ${ }^{35,36}$ Assessed within 48 hours after inclusion, Ducros et al. ${ }^{35}$ combined death, necessity of intubation, persistence of either all inclusion criteria or circulatory failure at 2 hours or reappearance after 2 hours. There was no difference in the composite outcome between the CPAP and usual care group. A secondary outcome was the composite primary endpoint without the intubation criteria. Frontin et al. ${ }^{36}$ used treatment success, defined as the respiratory rate less than 25 breaths per minute and $\mathrm{SpO}_{2}$ greater than $90 \%$ at the end of the 1-hour study.

Mortality was measured at different time points (Figure 3). Pre-hospital patient mortality, ${ }^{34}$ in-hospital mortality, ${ }^{35,38}$ and 30-day mortality ${ }^{36}$ were reported. Hubble et al. ${ }^{38}$ had the highest decrease in mortality, from 23\% in the non-CPAP group to 5.5\% in the CPAP group. Pooled results demonstrated an overall 59\% decrease in mortality, OR 0.41, 95\% CI 0.190.87 (Figure 4).

\section{INSERT FIGURE 4}

The sensitivity analysis could not be performed for the studies excluded because of quality. There was no denominator for the non-CPAP group in one study ${ }^{37}$ and there were no intubations in the CPAP group for the other. ${ }^{39}$ The studies did not report mortality. 
Changes in physiological values - respiratory rate, heart rate and blood pressure were also assessed, ${ }^{34-36,38}$ as shown in Table 3. Most studies reported physiological outcomes at 1 hour. Others reported the final set of physiological outcomes used recorded just before ED arrival. ${ }^{34}$ One study reported physiological values recorded at several intervals up to 6hours. ${ }^{35}$ When data points were not present in the final set, the immediately preceding complete set was used. ${ }^{34}$ Improvements in the changes of physiological values were inconsistent and had high heterogeneity, as shown in Table 4

Length of stay in ICU ${ }^{35,36}$ and hospital LOS $^{36,38}$ showed no difference (Table 4). The requirement for inotropic support ${ }^{36} 35$ was assessed in two studies and in one study BNP levels during the first 24 hours, peak troponin I level; cumulated doses of nitrates and diuretics were reported. ${ }^{35}$ Changes in BNP levels in the first 24 hours were similar in both groups. $^{35}$

Dyspnoea score was reported in two studies. ${ }^{36,38}$ Patients self-evaluated their perceived breathlessness using a scale ranging from 0 (no breathlessness) to 10 (maximal breathlessness). The reduction in dyspnoea score was significant in one study. ${ }^{38}$

Adverse events/complications such as mask intolerance, barotrauma, vomiting or gastric distension were also assessed. Two patients experienced vomiting in the CPAP group and three in the usual care group but adverse events such as mask intolerance, barotrauma, or gastric distension were not observed. ${ }^{34,36}$

\section{DISCUSSION}

This systematic review found seven studies that compared CPAP to non-CPAP treatment for patients with respiratory distress in the pre-hospital setting. Two studies ${ }^{37,39}$ did not compare baseline characteristics and were excluded from analyses of outcomes. Pooling the results of the five eligible studies, we demonstrated fewer intubations and decreased mortality when CPAP was used in the prehospital setting. There was wide variation in the intubation and mortality rates, from $0 \%$ to $50 \%$ for intubation and $0 \%$ to $35 \%$ for mortality in the non-CPAP 
groups. The variability may be related to the differences between health care systems. For example, the French EMS has mobile ICUs staffed by a physician (who is usually an experienced emergency physician or anaesthetist), a nurse and an emergency medical technician. ${ }^{36}$ In comparison, EMS systems in North America, United Kingdom and Australia ambulances are often staffed by paramedics who do not have the same clinical resources and expertise as mobile ICUs. Furthermore, Australian studies of critical illness have shown lower baseline and treatment mortality compared to international studies, ${ }^{40}$ and hence such dramatic improvements with CPAP may not be replicated in other health care contexts. Also, the exclusion of patients with "do not resuscitate" orders may influence outcomes. Patient outcomes that were not statistically significant in the two French RCTs in this systematic review and meta-analysis were likely due to the studies not being adequately powered for these outcomes.

The cause of respiratory failure may have influenced intubation and mortality rates but this was not examined in four studies. Logistic regression modelling of intubation outcomes by Thompson et $\mathrm{al}^{14}$ found, after adjustment for allocation to the CPAP group, female sex, age out-of-hospital, peripheral oxygen saturation, out-of-hospital respiratory rate, ED diagnosis of pneumonia and ED diagnosis of acute coronary syndrome that CPAP independently reduced the number of intubations (adjusted OR 0.16; 95\% CI 0.04 to 0.7). Studies of the hospital administration CPAP ${ }^{9-11,41-57}$ initially targeted APO, particularly ACPO and similarly studies of prehospital CPAP. ${ }^{17-20,25,34-36}$ Intubation for acute cardiogenic pulmonary oedema ranged from $5 \%$ to $6 \%$ for non-CPAP compared to 3 to $5 \%$ for the CPAP group and mortality varied for the non-CPAP group from $0 \%$ to $11 \%$ and CPAP group $0 \%$ to $5 \% .{ }^{34-36}$ Paramedic assessment of the medical history to identify patients with acute congestive heart failure among critically ill patients struggling to breathe in the prehospital-setting can be difficult. Correct identification of patients who meet eligibility criteria or whose treatment decisions depend on these data is important. Hubble and colleague's study ${ }^{38}$ of APO showed that $24 \%$ of patients did not have APO and for those who did, the intubation rate was $28 \%$ and mortality $25 \%$. With the exception of studies of patients treated by mobile ICU $^{17}$ feasibility studies of CPAP for patients with acute cardiogenic pulmonary oedema report 16-32\% of cases were misdiagnosed. ${ }^{16} 18$ Other diseases such as chronic obstructive pulmonary disease or asthma have also been treated by CPAP. ${ }^{23,58,59}$ Thompson et al. ${ }^{14}$ recruited patients with acute respiratory failure and reported an intubation rate of 50\% and in-hospital mortality of $35 \%$ in the non-CPAP group and 20\% and 14\% respectively in the CPAP group. Including all 
cases of severe acute respiratory failure in this systematic review increased the generalisability of the results, but there is a large variation in the number of intubations and mortality. Further research is required.

Mortality as an end point is objective and its clinical relevance is important but requires large sample size for valid assessment in the pre-hospital setting. Recruiting patients for these studies may be difficult. For example, Ducros et al. ${ }^{35}$ recruited only half of their estimated sample and had to terminate their study early because data collection time exceeded planned duration due to low patient recruitment. Treatments received and other factors after the patient has been transported to the ED may influence in-hospital or 30-day mortality greater than pre-hospital care. The number of intubations is also an important outcome because of the associated risks with intubation and higher costs associated with the ICU admission and longer hospital stay. The proportion of patients intubated and dying in the field is comparatively low so large sample sizes would need to be recruited to ensure the study has adequate power to detect significant differences. Surrogate measures such as physiological values are a substitute for a clinically meaningful end point that is a direct measure of how a patient feels, functions, or survives ${ }^{60}$ are used to assess the effect of the therapy. It is unknown if improvements in physiological values are associated with improved mortality and other patient-centred outcomes. Improvements in physiological values were reported but the results were inconsistent.

Dyspnoea, described as sensations of work or effort, tightness, or air hunger that is unsatisfied on inspiration, is a common and important symptom reported by patients with acute respiratory failure. ${ }^{61}$ To manage patients with symptoms of dyspnoea, dyspnoea should be assessed using appropriate measures. Two studies assessed dyspnoea in this systematic review but few reports describe dyspnoea scores in studies of pre-hospital CPAP. ${ }^{20,36,38}$ Visual analogue scales ${ }^{62-64}$ and the Borg dyspnoea scale ${ }^{65,66}$ are sensory-perceptual measures that include ratings of intensity or sensory quality. They are used in the pre-hospital setting but there are no validated instruments for dyspnoea assessment that have accuracy, reliability, reproducibility between observers, and are sensitive to important changes in dyspnoea. ${ }^{67}$ Further, assessment of dyspnoea is challenged because dyspnoea scores tend to improve regardless of intervention. ${ }^{67}$ 
Recent guidelines ${ }^{68}$ recommend CPAP in the prehospital setting administered by advancedlevel EMS providers in both urban and rural settings. ${ }^{59}$ The safety of administering CPAP has been reported in several small observational European and North American observational studies, ${ }^{16-18,34,37}$ Early CPAP, when compared to later CPAP, has been shown to have improved outcomes. ${ }^{20}$ Nevertheless, consideration must be given to the feasibility to delivering CPAP in the pre-hospital setting. Devices to deliver CPAP are often driven by oxygen and large volumes may be required. Ambulances must have the capacity to carry sufficient amounts of oxygen to ensure availability of oxygen from any distance to definitive care that is required. Furthermore its potential benefit must be weighed against possible transport delays for critically ill patients.

\section{Limitations}

Five studies were reviewed in this systematic review and meta-analysis. We did not include non-English language papers so we have may have missed some relevant papers. We may have also missed some relevant English-language papers but we conducted an extensive systematic, literature review to minimise this.

We included non-randomised trials and observation studies provided that they compared the baseline characteristics. Non-randomised studies have inherent biases due to the non-random allocation of the intervention. The risk of potential selection bias from the study conducted by Dib et al. ${ }^{34}$ was high, e.g. from non-randomization of patients, and patients and paramedics not being blinded to treatment. The investigators also acknowledge that the reason that patients did not receive CPAP was largely because of paramedic inexperience in administering the treatment. ${ }^{34}$ The method of data collection also increased the risk for bias. The identification of acute congestive heart failure was made by two physicians who accessed patients' history, treatment and outcomes from a retrospective chart review. Paramedics in the field usually do not have access to this information. Inspired oxygen concentration per CPAP level should be titrated to achieve a target $\mathrm{SpO}_{2}$ Hyperoxia is potentially linked to worse outcomes (e.g. myocardial infarction, COPD). ${ }^{33}$ Titrating oxygen and CPAP levels to achieve a target $\mathrm{SpO}_{2}$ should be evaluated in future trials. The use of concurrent controls and adjustment for potential confounding factors in regression models ${ }^{38}$ reduces the potential risk for bias. It is likely that some potential confounders are unknown. For example, there is no way to know that more than one episode for a patient has been included in the study unless declared by the authors and this information may not be reported. 
Also, not knowing whether intubation has been withheld could be significant to the interpretation of the findings. We assessed studies for methodological quality, based on the evaluation system recommended by Ryan et al. ${ }^{28}$ and the Cochrane Collaboration. ${ }^{29}$ All of the papers were from developed countries and it is unknown if the results from this systematic and meta-analysis would be different if studies had been conducted in other settings.

\section{CONCLUSION}

The studies included in this review showed a reduction in the number of intubations and mortality in patients with acute respiratory failure who received CPAP in the pre-hospital setting. The results may not be applicable to other health care contexts because of the inherent differences in the organisation and staffing of the EMS. Limitations of this systematic review and meta-analysis are the small number of studies and even fewer RCTs. Information from large RCTs on the efficacy of CPAP initiated early in the pre-hospital setting is critical to establishing the evidence base underpinning this therapy prior to ambulance services incorporating CPAP as routine clinical practice.

Several small studies have shown a reduction in the rate of intubations and mortality in patients administered CPAP for acute respiratory failure in the pre-hospital setting. The results may not be applicable to other health care contexts because of the inherent differences in the organisation and staffing of the EMS. Information on the efficacy of CPAP initiated early in the pre-hospital setting is critical to establishing the evidence base underpinning this therapy prior to ambulance services incorporating CPAP as routine clinical practice.

\section{ACKNOWLEDGEMENT}

We thank Alexandra Bremner (PhD, Lecturer in Biostatistics, The University of Western Australia) for her statistical advice in the preparation of this manuscript.

\section{CONFLICT OF INTEREST STATEMENT}

TAW is a NH\&MRC Clinical Research Postdoctoral Fellow

JF receives partial salary support from St John Ambulance (WA)

GDP - no conflict of interest

IJ is the Clinical Services Director for St John Ambulance (Western Australia). 
St John Ambulance (WA) played no role in the study design, conduct or interpretation of the results.

\section{REFERENCES}

1. $\quad$ Krum H, Abraham WT. Heart failure. Lancet 2009;373:941-55.

2. National Heart Foundation of Australia, and the Cardiac Society of Australia, and New Zealand (Chronic Heart Failure Guidelines Expert Writing Panel). Guidelines for the prevention, detection and management of chronic heart failure in Australia. Updated October 2011. Available from http://www.heartfoundation.org.au/SiteCollectionDocuments/Chronic_Heart_Failure_Guidelines_2011.pdf Accessed Feb 2012. 2011.

3. Ware LB, Matthay MA. Clinical practice. Acute pulmonary edema. N Engl J Med 2005;353:2788-96.

4. $\quad$ Pang D, Keenan SP, Cook DJ, et al. The effect of positive pressure airway support on mortality and the need for intubation in cardiogenic pulmonary edema: a systematic review. Chest 1998;114:1185-92.

5. Chadda K, Annane D, Hart N, et al. Cardiac and respiratory effects of continuous positive airway pressure and noninvasive ventilation in acute cardiac pulmonary edema. Crit Care Med 2002;30:2457-61.

6. Lenique F, Habis M, Lofaso F, et al. Ventilatory and hemodynamic effects of continuous positive airway pressure in left heart failure. Am J Respir Crit Care Med 1997;155:500-5.

7. Mariani J, Macchia A, Belziti C, et al. Noninvasive ventilation in acute cardiogenic pulmonary edema: a meta-analysis of randomized controlled trials. J Card Fail 2011;17:850-9.

8. Weng C-L, Zhao Y-T, Liu Q-H, et al. Meta-analysis: Noninvasive ventilation in acute cardiogenic pulmonary edema. Ann Intern Med 2010;152:590-600.

9. Masip J. Noninvasive ventilation in acute cardiogenic pulmonary edema. Curr Opin Crit Care 2008;14:531-5.

10. Peter JV, Moran JL, Phillips-Hughes J, et al. Effect of non-invasive positive pressure ventilation (NIPPV) on mortality in patients with acute cardiogenic pulmonary oedema: a meta-analysis. Lancet 2006;367:1155-63.

11. Masip J, Roque M, Sanchez B, et al. Noninvasive ventilation in acute cardiogenic pulmonary edema: systematic review and meta-analysis. Jama 2005;294:3124-30.

12. Vital FMR, Saconato H, Ladeira MT, et al. Non-invasive positive pressure ventilation (CPAP or bilevel NPPV) for cardiogenic pulmonary edema. The Cochrane database of systematic reviews 2008:CD005351.

13. Keenan SP, Kernerman PD, Cook DJ, et al. Effect of noninvasive positive pressure ventilation on mortality in patients admitted with acute respiratory failure: a meta-analysis. Crit Care Med 1997;25:1685-92.

14. Thompson J, Petrie DA, Ackroyd-Stolarz S, et al. Out-of-hospital continuous positive airway pressure ventilation versus usual care in acute respiratory failure: a randomized controlled trial. Ann Emerg Med 2008;52:232-41.

15. Maio RF, Garrison HG, Spaite DW, et al. Emergency medical services outcomes project I (EMSOP I): prioritizing conditions for outcomes research. Ann Emerg Med 1999;33:423-32.

16. Dieperink W, Weelink EEM, van der Horst ICC, et al. Treatment of presumed acute cardiogenic pulmonary oedema in an ambulance system by nurses using Boussignac continuous positive airway pressure. Emerg Med J 2009;26:141-4.

17. Kallio T, Kuisma M, Alaspaa A, et al. The use of prehospital continuous positive airway pressure treatment in presumed acute severe pulmonary edema. Prehosp Emerg Care 2003;7:209-13.

18. Kosowsky JM, Stephanides SL, Branson RD, et al. Prehospital use of continuous positive airway pressure (CPAP) for presumed pulmonary edema: a preliminary case series. Prehosp Emerg Care 2001;5:190-6.

19. Templier F, Dolveck F, Baer M, et al. 'Boussignac' continuous positive airway pressure system: practical use in a prehospital medical care unit. Eur J Emerg Med 2003;10:87-93.

20. Plaisance P, Pirracchio R, Berton C, et al. A randomized study of out-of-hospital continuous positive airway pressure for acute cardiogenic pulmonary oedema: physiological and clinical effects. Eur Heart J 2007;28:2895-901.

21. Foti G, Sangalli F, Berra L, et al. Is helmet CPAP first line pre-hospital treatment of presumed severe acute pulmonary edema? Intensive Care Med 2009;35:656-62.

22. Taylor D, Bernard SA, Masci K, et al. Prehospital noninvasive ventilation: a viable treatment option in the urban setting. Prehosp Emerg Care 2008;12:42-5. 
23. Schmidbauer W, Ahlers O, Spies C, et al. Early prehospital use of non-invasive ventilation improves acute respiratory failure in acute exacerbation of chronic obstructive pulmonary disease. Emerg Med J 2011;28:626-7.

24. Craven RA, Singletary N, Bosken L, et al. Use of bilevel positive airway pressure in out-of-hospital patients. Acad Emerg Med 2000;7:1065-8.

25. Weitz G, Struck J, Zonak A, et al. Prehospital noninvasive pressure support ventilation for acute cardiogenic pulmonary edema. Eur J Emerg Med 2007;14:276-9.

26. Bruge P, Jabre P, Dru M, et al. An observational study of noninvasive positive pressure ventilation in an out-of-hospital setting. Am J Emerg Med 2008;26:165-9.

27. Roessler MS, Schmid DS, Michels P, et al. Early out-of-hospital non-invasive ventilation is superior to standard medical treatment in patients with acute respiratory failure: a pilot study. Emerg Med J 2012;29:409-

14.

28. Ryan R, Hill S, Prictor M, et al. Study Quality Guide. May 2011

http://www.latrobe.edu.au/chcp/cochrane/resources.html (accessed 4 April 2012). 2011.

29. Higgins J, Green S, (editors). Cochrane Handbook for Systematic Reviews of Interventions Version 5.1.0 [updated March 2011]. The Cochrane Collaboration, 2011. Available from www.cochrane-handbook.org. (accessed 29 Mar 2011). 2011.

30. Higgins JPT, Thompson SG, Deeks JJ, et al. Measuring inconsistency in meta-analyses. BMJ 2003;327:557-60.

31. Sterne JA, Egger M. Funnel plots for detecting bias in meta-analysis: guidelines on choice of axis. J Clin Epidemiol 2001;54:1046-55.

32. Moher D, Liberati A, Tetzlaff J, et al. Preferred reporting items for systematic reviews and metaanalyses: the PRISMA statement. J Clin Epidemiol 2009;62:1006-12.

33. Bledsoe BE, Anderson E, Hodnick R, et al. Low-Fractional Oxygen Concentration Continuous Positive Airway Pressure is Effective in the Prehospital Setting. Prehosp Emerg Care 2012;16:217-21.

34. Dib JE, Matin SA, Luckert A. Prehospital use of continuous positive airway pressure for acute severe congestive heart failure. J Emerg Med 2012;42:553-8.

35. Ducros L, Logeart D, Vicaut E, et al. CPAP for acute cardiogenic pulmonary oedema from out-ofhospital to cardiac intensive care unit: a randomised multicentre study. Intensive Care Med 2011;37:1501-9. 36. Frontin P, Bounes V, Houze-Cerfon $\mathrm{CH}$, et al. Continuous positive airway pressure for cardiogenic pulmonary edema: a randomized study. Am J Emerg Med 2011;29:775-81.

37. Hastings D, Monahan J, Gray C, et al. CPAP. A supportive adjunct for congestive heart failure in the prehospital setting. J Emerg Med Serv JEMS 1998;23:58-65.

38. Hubble MW, Richards ME, Jarvis R, et al. Effectiveness of prehospital continuous positive airway pressure in the management of acute pulmonary edema. Prehosp Emerg Care 2006;10:430-9.

39. Warner GS. Evaluation of the effect of prehospital application of continuous positive airway pressure therapy in acute respiratory distress. Prehospital Disaster Med 2010;25:87-91.

40. Bellomo R, Stow PJ, Hart GK. Why is there such a difference in outcome between Australian intensive care units and others? Curr Opin Anaesthesiol 2007;20:100-5.

41. Gray A, Goodacre S, Newby DE, et al. Noninvasive ventilation in acute cardiogenic pulmonary edema. N Engl J Med 2008;359:142-51.

42. Tallman TA, Peacock WF, Emerman CL, et al. Noninvasive ventilation outcomes in 2,430 acute decompensated heart failure patients: an ADHERE Registry Analysis. Acad Emerg Med 2008;15:355-62. 43. L'Her E, Duquesne F, Girou E, et al. Noninvasive continuous positive airway pressure in elderly cardiogenic pulmonary edema patients. Intensive Care Med 2004;30:882-8.

44. Nava S, Carbone G, DiBattista N, et al. Noninvasive ventilation in cardiogenic pulmonary edema: a multicenter randomized trial. Am J Respir Crit Care Med 2003;168:1432-7.

45. Park M, Sangean MC, Volpe MdS, et al. Randomized, prospective trial of oxygen, continuous positive airway pressure, and bilevel positive airway pressure by face mask in acute cardiogenic pulmonary edema. Crit Care Med 2004;32:2407-15.

46. Crane SD, Elliott MW, Gilligan P, et al. Randomised controlled comparison of continuous positive airways pressure, bilevel non-invasive ventilation, and standard treatment in emergency department patients with acute cardiogenic pulmonary oedema. Emerg Med J 2004;21:155-61.

47. Kelly CA, Newby DE, Mcdonagh TA, et al. Randomised controlled trial of continuous positive airway pressure and standard oxygen therapy in acute pulmonary oedema. Effects on plasma brain natriuretic peptide concentrations. Eur Heart J 2002;23:1379-86.

48. Levitt MA. A prospective, randomized trial of BiPAP in severe acute congestive heart failure. J Emerg Med 2001;21:363-9. 
49. Park M, Lorenzi-Filho G, Feltrim MI, et al. Oxygen therapy, continuous positive airway pressure, or noninvasive bilevel positive pressure ventilation in the treatment of acute cardiogenic pulmonary edema. Arq Bras Cardiol 2001;76:221-30.

50. Masip J, Betbese AJ, Paez J, et al. Non-invasive pressure support ventilation versus conventional oxygen therapy in acute cardiogenic pulmonary oedema: a randomised trial. Lancet 2000;356:2126-32.

51. Kosowsky JM, Storrow AB, Carleton SC. Continuous and bilevel positive airway pressure in the treatment of acute cardiogenic pulmonary edema. Am J Emerg Med 2000;18:91-5.

52. Takeda S, Nejima J, Takano T, et al. Effect of nasal continuous positive airway pressure on pulmonary edema complicating acute myocardial infarction. Jpn Circ J 1998;62:553-8.

53. Takeda S, Takano T, Ogawa R. The effect of nasal continuous positive airway pressure on plasma endothelin-1 concentrations in patients with severe cardiogenic pulmonary edema. Anesth Analg 1997;84:10916.

54. Lin M, Yang YF, Chiang HT, et al. Reappraisal of continuous positive airway pressure therapy in acute cardiogenic pulmonary edema. Short-term results and long-term follow-up. Chest 1995;107:1379-86.

55. Bersten AD, Holt AW, Vedig AE, et al. Treatment of severe cardiogenic pulmonary edema with continuous positive airway pressure delivered by face mask. N Engl J Med 1991;325:1825-30.

56. Vaisanen IT, Rasanen J. Continuous positive airway pressure and supplemental oxygen in the treatment of cardiogenic pulmonary edema. Chest 1987;92:481-5.

57. Rasanen J, Heikkila J, Downs J, et al. Continuous positive airway pressure by face mask in acute cardiogenic pulmonary edema. Am J Cardiol 1985;55:296-300.

58. Soroksky A, Stav D, Shpirer I. A pilot prospective, randomized, placebo-controlled trial of bilevel positive airway pressure in acute asthmatic attack. Chest 2003;123:1018-25.

59. Ram FSF, Wellington S, Rowe B, et al. Non-invasive positive pressure ventilation for treatment of respiratory failure due to severe acute exacerbations of asthma. The Cochrane database of systematic reviews 2005:CD004360.

60. Prentice RL. Surrogate endpoints in clinical trials: definition and operational criteria. Stat Med 1989;8:431-40.

61. Parshall MB, Schwartzstein RM, Adams L, et al. An official American Thoracic Society statement: update on the mechanisms, assessment, and management of dyspnea. Am J Respir Crit Care Med 2012;185:43552.

62. Aitken RC. Measurement of feelings using visual analogue scales. Proc R Soc Med 1969;62:989-93.

63. Gift AG. Validation of a vertical visual analogue scale as a measure of clinical dyspnea. Rehabil Nurs 1989;14:323-5.

64. Gift AG. Visual analogue scales: measurement of subjective phenomena. Nurs Res 1989;38:286-8.

65. Borg G. Perceived exertion as an indicator of somatic stress. Scand J Rehabil Med 1970;2:92-8.

66. Borg G. Psychophysical bases of perceived exertion. Med Sci Sports Exerc 1982;14:377-81.

67. Allen LA, Hernandez AF, O'Connor CM, et al. End points for clinical trials in acute heart failure syndromes. J Am Coll Cardiol 2009;53:2248-58.

68. Daily JC, Wang HE. Noninvasive positive pressure ventilation: resource document for the National Association of EMS Physicians position statement. Prehosp Emerg Care 2011;15:432-8. 


\section{FIGURE LEGEND}

Figure 1. Flow diagram of study selection

Figure 2. Publication bias

Figure 3. Forrest plot showing the pooled estimate of effect of CPAP on the risk of intubation

Figure 4. Forrest plot showing the pooled estimate of effect of CPAP on the risk of mortality

Figure 1. Flow diagram of study selection

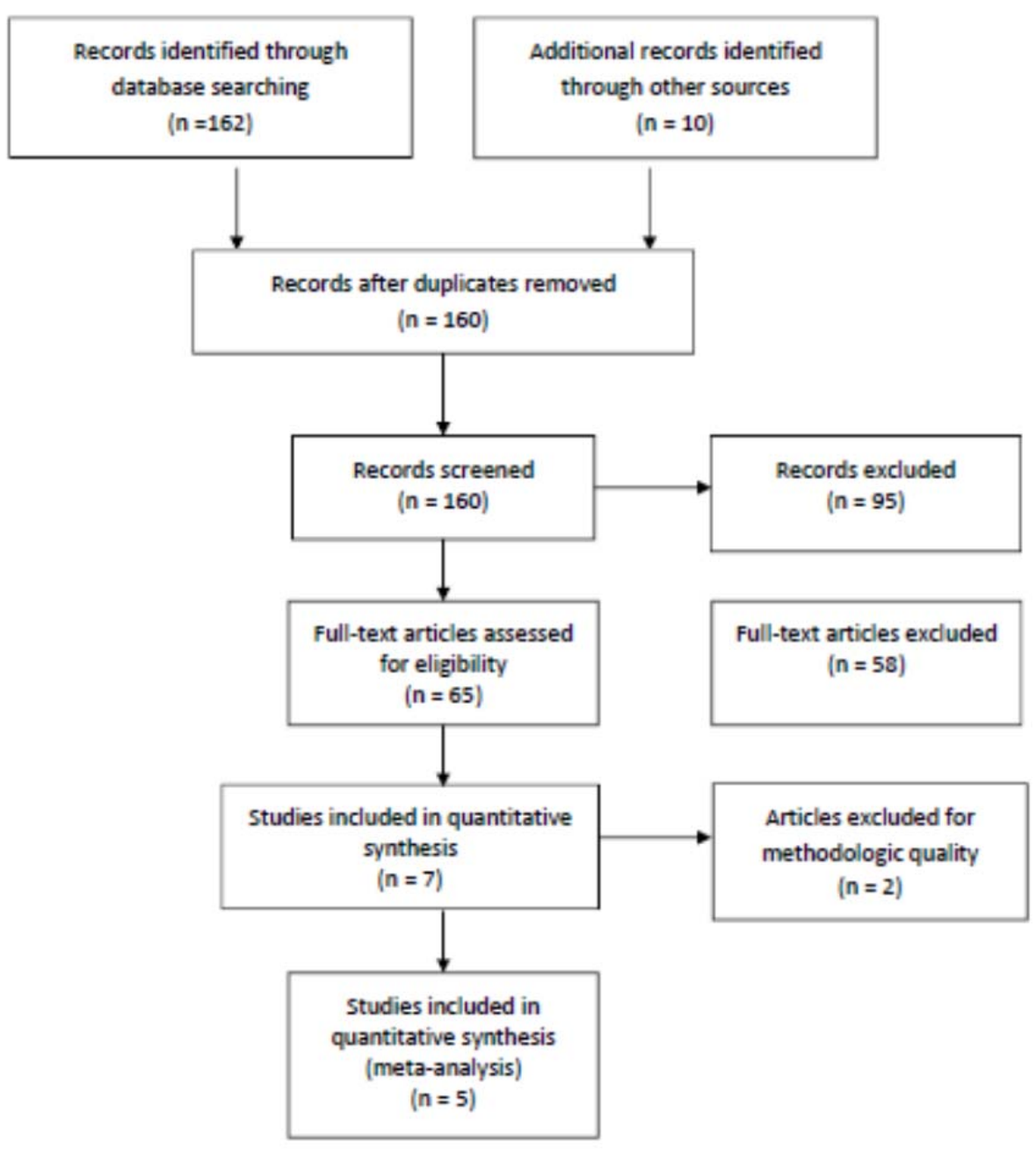


Figure 2. Publication bias

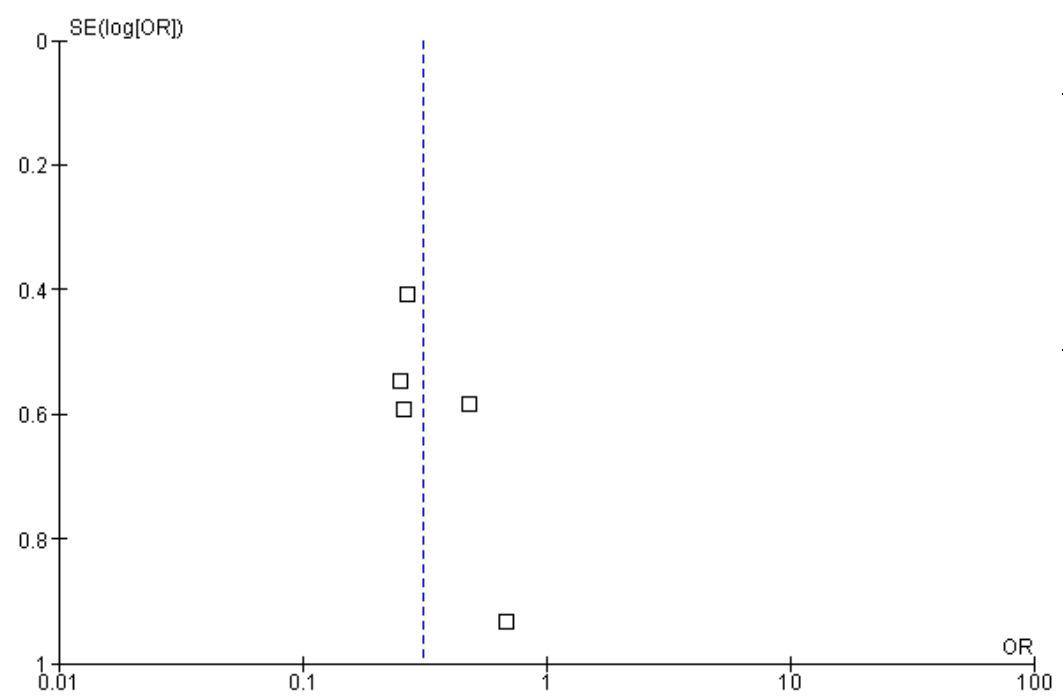

Figure legend

$x$-axis odds ratio (OR)

$y$-axis standard error of the

log odds ratio (SE log OR))

Figure 3. Forrest plot showing the pooled estimate of effect of CPAP on the risk of intubation

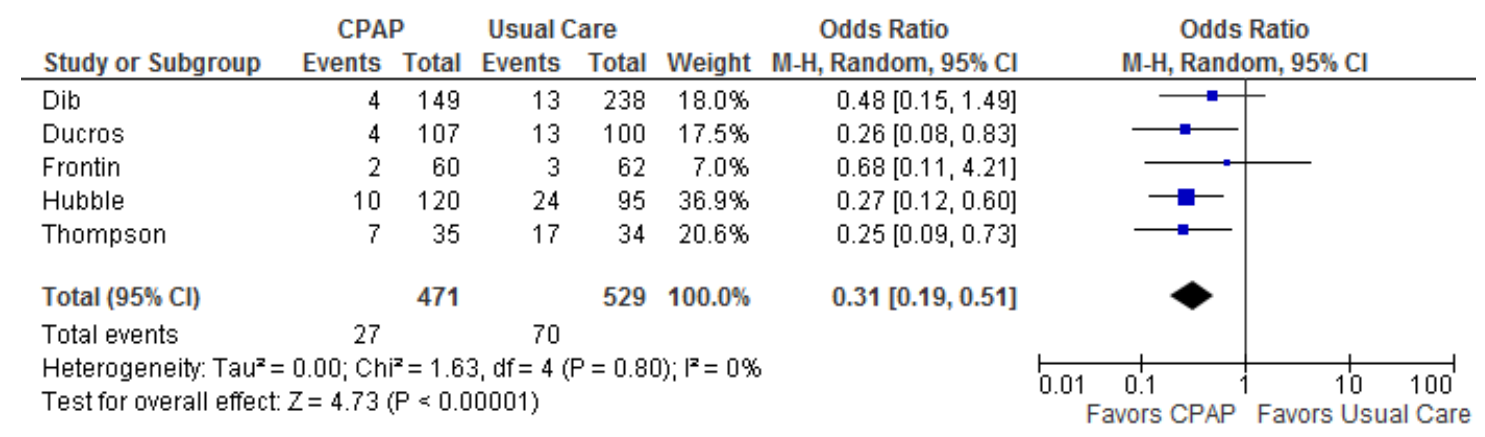

Figure 4. Forrest plot showing the pooled estimate of effect of CPAP on the risk of mortality

\begin{tabular}{|c|c|c|c|c|c|c|c|c|}
\hline \multirow[b]{2}{*}{ Study or Subgroup } & \multicolumn{2}{|c|}{ CPAP } & \multicolumn{2}{|c|}{ Usual Care } & \multirow[b]{2}{*}{ Weight } & \multirow{2}{*}{$\begin{array}{c}\text { Odds Ratio } \\
\text { M-H, Random, } 95 \% \mathrm{Cl}\end{array}$} & \multirow{2}{*}{\multicolumn{2}{|c|}{$\begin{array}{c}\text { Odds Ratio } \\
\text { M-H, Random, } 95 \% \mathrm{Cl}\end{array}$}} \\
\hline & Events & Total & Events & Total & & & & \\
\hline Dib & 0 & 149 & 0 & 238 & & Not estimable & & \\
\hline Ducros & 4 & 107 & 5 & 100 & $20.6 \%$ & $0.74[0.19,2.83]$ & & \\
\hline Frontin & 6 & 60 & 7 & 62 & $24.8 \%$ & $0.87[0.28,2.77]$ & & \\
\hline Hubble & 6 & 120 & 21 & 95 & $30.4 \%$ & $0.19[0.07,0.48]$ & & \\
\hline Thompson & 5 & 35 & 12 & 34 & $24.2 \%$ & $0.31[0.09,0.99]$ & & \\
\hline Total $(95 \% \mathrm{Cl})$ & & 471 & & 529 & $100.0 \%$ & $0.41[0.19,0.87]$ & & \\
\hline Total events & 21 & & 45 & & & & & \\
\hline $\begin{array}{l}\text { Heterogeneity: Tau } \\
\text { Test for overall effect }\end{array}$ & $\begin{array}{l}0.26 ; \mathrm{Ch} \\
\mathrm{Z}=2.32\end{array}$ & $\begin{array}{l}P=5.2 \\
P=0.0\end{array}$ & $\begin{array}{l}5, d f=3 \\
\text { 2) }\end{array}$ & $P=0.15$ & 5); $I^{2}=439$ & & $\begin{array}{|cc|}0.01 & 0.1 \\
& 0.1 \\
& \text { Favors CPAP }\end{array}$ & 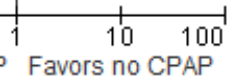 \\
\hline
\end{tabular}


Table 1. Studies that met the inclusion criteria for this systematic review before assessment of the study quality

\begin{tabular}{|c|c|c|c|c|}
\hline Study & $\begin{array}{l}\text { Emergency Medical } \\
\text { Service }\end{array}$ & Design & Selection criteria & $\begin{array}{l}\text { Number of } \\
\text { patients }\end{array}$ \\
\hline Dib et al. $(2012)^{34}$ & $\begin{array}{l}\text { EMS, New Jersey } \\
\text { Paramedics } \\
\text { Two-tier EMS system: } \\
\text { BLS and ALS } \\
\text { ALS only to those } \\
\text { calls requiring } \\
\text { possible ALS care } \\
\text { and intervention, e.g. } \\
\text { shortness of breath }\end{array}$ & $\begin{array}{l}\text { Retrospective review } \\
\text { prehospital charts } \\
\text { January } 2005 \text {-December } \\
2006 \\
\text { Ethic Committee approval }\end{array}$ & $\begin{array}{l}\text { Patients treated for severe acute CHF if } \\
\text { - Respiratory rate }>25 \text { breaths per } \\
\text { minute } \\
\text { - Laboured and shallow breathing } \\
\text { - Bilateral rales } \\
\text { - History of CHF } \\
\text { - Intact mental status }\end{array}$ & $\begin{array}{l}387 \text { patients: } \\
\text { CPAP = } 149 \\
\text { Non-CPAP }=238\end{array}$ \\
\hline $\begin{array}{l}\text { Ducros et al. } \\
(2011)^{35}\end{array}$ & $\begin{array}{l}\text { French mobile } \\
\text { medical units } \\
\text { (Physician staffed) }\end{array}$ & $\begin{array}{l}\text { Multicentre RCT } \\
\text { Control group - standard } \\
\text { treatment } \\
\text { Experimental group - } \\
\text { standard treatment plus } \\
\text { CPAP } \\
\text { Ethic Committee approval }\end{array}$ & $\begin{array}{l}\text { Included patients with cardiogenic } \\
\text { pulmonary oedema if } \\
\text { - Orthopnoea } \\
\text { - Respiratory rate > } 25 \text { breaths per } \\
\text { minute } \\
\text { - } \mathrm{SpO}_{2} \text { less than } 90 \% \text { in room air } \\
\text { - Diffuse crackles } \\
\text { Excluded } \\
\text { - History of COPD, asthma, severe } \\
\text { stenotic valve disease } \\
\text { - Immediate indication for intubation } \\
\text { (severe impairment of } \\
\text { consciousness, bradypnoea) } \\
\text { - Cardiovascular collapse or suspicion } \\
\text { of STEMl }\end{array}$ & $\begin{array}{l}207 \text { patients: } \\
\text { CPAP = } 107 \\
\text { Non-CPAP = } 100 \\
\text { Baseline } \\
\text { demographics } \\
\text { and physiological } \\
\text { values similar } \\
\text { between groups } \\
\text { Sample size } \\
\text { estimated at } 200 \\
\text { patients per group } \\
\text { Data collection } \\
\text { time exceeded } \\
\text { planned duration } \\
\text { due to low patient } \\
\text { recruitment, trial } \\
\text { stopped after } 207 \\
\text { patients }\end{array}$ \\
\hline $\begin{array}{l}\text { Frontin et al. } \\
(2011)^{36}\end{array}$ & $\begin{array}{l}\text { Mobile ICU (Physician } \\
\text { staffed) } \\
\text { Prehospital } \\
\text { emergency service of } \\
\text { University Hospital in } \\
\text { metropolitan area } \\
\text { Toulouse, France }\end{array}$ & $\begin{array}{l}\text { Single centre RCT } \\
\text { September } 2006 \text { and March } \\
2008 \\
\text { Ethic Committee approval }\end{array}$ & $\begin{array}{l}\text { Out-of-hospital patients in severe } \\
\text { acute cardiogenic pulmonary oedema } \\
\text { Included } \\
\text { - } \text { Age >= } 18 \text { years } \\
\text { - Respiratory rate > } 25 \mathrm{bpm} \\
\text { - Orthopnoea } \\
\text { - } \quad \text { Diffuse crackles without evidence } \\
\text { of pulmonary aspiration or } \\
\text { infection } \\
\text { - SpO2 }<90 \% \\
\text { Excluded } \\
\text { - cardiovascular collapse } \\
\text { - Impaired consciousness } \\
\text { - AMI } \\
\text { - Immediate need for intubation } \\
\text { - History gastric surgery (<8 days) } \\
\text { - Vomiting }\end{array}$ & $\begin{array}{l}124 \text { patients: } \\
\text { CPAP = } 60 \\
\text { Non-CPAP = } 62 \\
2 \text { did not consent } \\
\text { Similar baseline } \\
\text { characteristics } \\
\text { and non- } \\
\text { significant trend } \\
\text { toward difference } \\
\text { in rate of previous } \\
\text { ACPE between } \\
\text { the groups }\end{array}$ \\
\hline $\begin{array}{l}\text { Hastings et } \\
\text { al.(1998) }{ }^{37}\end{array}$ & $\begin{array}{l}\text { Paramedics } \\
\text { Galveston, United } \\
\text { States of America }\end{array}$ & $\begin{array}{l}\text { Before and after 6-month } \\
\text { study } \\
\text { Before: Retrospective chart } \\
\text { review of patients matching } \\
\text { study inclusion criteria pre } \\
\text { introduction of nasal CPAP } \\
\text { After Data collection } \\
\text { Ethics approval not stated }\end{array}$ & $\begin{array}{l}\text { Severe respiratory distress with APO } \\
\text { secondary to congestive heart failure } \\
\text { and renal failure. } \\
\text { Signs and symptoms include: } \\
\text { - Tachypnoeic } \\
\text { - Tachycardia } \\
\text { - Diaphoretis } \\
\text { - Hypertension } \\
\text { - Verbal impairment } \\
\text { - } \mathrm{SpO}_{2<}<0 \%\end{array}$ & $\begin{array}{l}\text { CPAP group }=32 \\
\text { Age ranged from } \\
50 \text { to } 90 \text { years } \\
\text { Comparator } \\
\text { group: number } \\
\text { and } \\
\text { characteristics of } \\
\text { patients not } \\
\text { stated }\end{array}$ \\
\hline
\end{tabular}




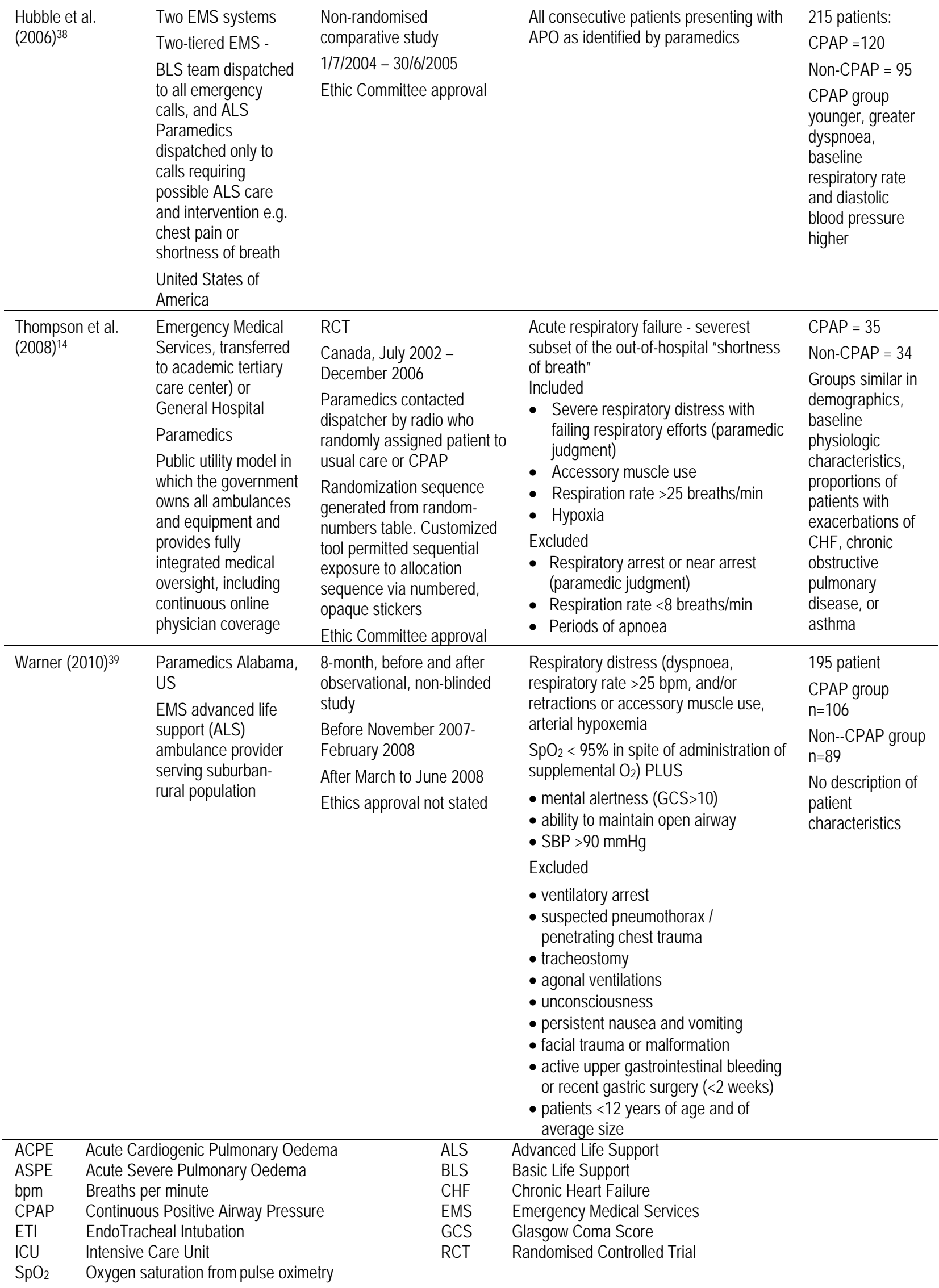


Table 2 Study quality and potential risk of bias

\begin{tabular}{|c|c|c|c|c|c|c|c|}
\hline & $\begin{array}{l}\text { Dib et al. } \\
(2011)^{34}\end{array}$ & $\begin{array}{l}\text { Ducros et } \\
\text { al. }(2011)^{35}\end{array}$ & $\begin{array}{l}\text { Frontin et al. } \\
(2011)^{36}\end{array}$ & $\begin{array}{l}\text { Hubble et } \\
\text { al. }(2006)^{38}\end{array}$ & $\begin{array}{l}\text { Hastings et } \\
\text { al. }(1998)^{37}\end{array}$ & $\begin{array}{l}\text { Thompson } \\
\text { et al. }{ }^{4}\end{array}$ & $\begin{array}{l}\text { Warner et } \\
\text { al. }{ }^{39}\end{array}$ \\
\hline Allocation concealment & $\begin{array}{l}\text { Randomi } \\
\text { sation } \\
\text { not done }\end{array}$ & Adequate* & Adequate* & $\begin{array}{l}\text { Randomisa } \\
\text { tion not } \\
\text { done }\end{array}$ & $\begin{array}{l}\text { Randomisa } \\
\text { tion not } \\
\text { done }\end{array}$ & Adequate* & $\begin{array}{l}\text { Randomisa } \\
\text { tion not } \\
\text { done }\end{array}$ \\
\hline Study blinded & No & No & No & No & No & No & No \\
\hline $\begin{array}{l}\text { Adherence to intention-to- } \\
\text { treat principle }\end{array}$ & No & Yes & $\begin{array}{l}\text { No, } 2 \text { patients } \\
(2 \%) \\
\text { randomised } \\
\text { but consent } \\
\text { withdrawn } \\
\text { (both CPAP } \\
\text { group) }\end{array}$ & Yes & No & No & No \\
\hline Patients lost to follow-up & Nil & Nil & $\begin{array}{l}2 \text { patients } \\
(2 \%) \\
\text { randomised } \\
\text { but consent } \\
\text { withdrawn } \\
\text { (both CPAP } \\
\text { group) }\end{array}$ & Nil & Not stated & One & Not stated \\
\hline Informed consent obtained & Yes & Yes & Yes & $\begin{array}{l}\text { Waiver of } \\
\text { consent }\end{array}$ & No & Yes & No \\
\hline $\begin{array}{l}\text { Groups comparable at } \\
\text { baseline }\end{array}$ & Yes & Yes & Yes & Yes & Unknown & Yes & Unknown \\
\hline
\end{tabular}

* adequate $=$ randomisation method would not enable the investigator or participant to know or influence allocation intervention group before an eligible participant was entered in the study ${ }^{28}$ 
Table 3. Summary of results from comparative studies

\begin{tabular}{|c|c|c|c|c|}
\hline Study & Outcome & Non-CPAP & CPAP & 'p' value / OR \& Cl \\
\hline $\begin{array}{l}\text { Dib et al. }(2011)^{34} \\
\text { Non-CPAP }=238 \\
\text { CPAP }=149\end{array}$ & $\begin{array}{l}\text { Pre-hospital time* (minutes) } \\
\text { Physiological changes } \\
\text { - } \quad \text { Respiratory rate decrease } \\
\text { - } \mathrm{SaO}_{2} \text { increased } \\
\text { - } \quad \mathrm{SBP} \text { reduction } \\
\text { - } \quad \mathrm{DBP} \text { reduction } \\
\text { - } \quad \text { Heart rate reduction } \\
\text { Pre-hospital intubation } \mathrm{n}(\%) \\
\text { Mortality }\end{array}$ & $\begin{array}{c}31 \\
4.09 \mathrm{bpm} \\
5 \% \\
19.9 \mathrm{~mm} \mathrm{Hg} \\
7.4 \mathrm{~mm} \mathrm{Hg} \\
9.6 \text { beats/min } \\
11(5.5 \%) \\
\text { Nil }\end{array}$ & $\begin{array}{c}30 \\
\\
5.63 \mathrm{bpm} \\
9 \% \\
27.1 \mathrm{~mm} \mathrm{Hg} \\
14.1 \mathrm{~mm} \mathrm{Hg} \\
17.2 \text { beats } / \mathrm{min} \\
4(2.6 \%) \\
\text { Nil }\end{array}$ & $\begin{array}{c}>0.01 \\
<0.01 \\
<0.01 \\
<0.01 \\
0.01 \\
<0.01 \\
<0.01\end{array}$ \\
\hline $\begin{array}{l}\text { Ducros et al. }(2011)^{35} \\
\text { Non-CPAP }=100 \\
\text { CPAP }=107\end{array}$ & $\begin{array}{l}\text { Median time between recruitment } \\
\text { and hospital admission (IQR) } \\
\text { Physiological changes Time } 0 \text { (H0) } \\
\text { to } 6 \text { hours (H6) } \\
\text { - } \quad \text { Respiratory rate reduction } \\
\text { - } \quad \text { SBP reduction } \\
\text { - } \quad \text { DBP reduction } \\
\text { - } \quad \text { Heart rate reduction } \\
\text { Successful treatment within first } 48 \\
\text { hours = absence of death, } \\
\text { intubation criteria \& persistence of } \\
\text { either all inclusion criteria or } \\
\text { circulatory failure } 2-48 \text { hours } \\
\text { Persistence of inclusion criteria } \\
\text { after } 2 \text { hours } \\
\text { Met intubation criteria within } 48 \\
\text { hours } \\
\text { Intubated within } 48 \text { hours } \\
\text { Mortality n (\%) } \\
\text { Median ICU LOS }\end{array}$ & $\begin{array}{c}82 \mathrm{~min}(69,95) \\
\\
6 \mathrm{bpm} \\
35 \mathrm{~mm} \mathrm{Hg} \\
25 \mathrm{~mm} \mathrm{Hg} \\
20 \text { beats/min } \\
63(63 \%)\end{array}$ & $\begin{array}{l}88 \mathrm{~min}(75,104) \\
8 \mathrm{bpm} \\
19 \mathrm{~mm} \mathrm{Hg} \\
16 \mathrm{~mm} \mathrm{Hg} \\
6 \text { beats/min } \\
84(79 \%) \\
\\
12(12 \%) \\
4(4 \%) \\
5(5 \%) \\
4(4 \%) \\
2 \text { days }\end{array}$ & $\begin{array}{c}0.001 \\
0.52 \\
0.035 \\
0.023 \\
\text { OR 2.1; } 95 \% \mathrm{Cl} 1.2 \text { to } 4.0 \\
\text { OR 2.5; } 95 \% \mathrm{Cl} 1.2 \text { to } 5.5 \\
\text { OR 3.9, } 95 \% \mathrm{Cl} 1.2,12.5 \\
\text { OR 3.9; } 95 \% \mathrm{Cl} 1.2 \text { to } 12.5 \\
\text { OR } 1.4 ; 95 \% \mathrm{Cl} 0.4 \text { to } 5.2 \\
0.67\end{array}$ \\
\hline $\begin{array}{l}\text { Frontin et al. }(2011)^{36} \\
\text { Non-CPAP }=62 \\
\text { CPAP }=60\end{array}$ & $\begin{array}{l}\text { Treatment success, i.e. respiratory } \\
\text { rate }<25 \text { bpm and oxygen } \\
\text { saturation }>90 \% \text { at the end of } 1 \text { - } \\
\text { hour study } \\
\text { Physiology changes at } 1 \text { hour } \\
\text { - } \quad \text { Mean respiratory rate (bpm) } \\
\text { - } \quad \text { Mean } \mathrm{SpO}_{2} \\
\text { - } \quad \text { Mean heart rate } \\
\text { - } \quad \text { Mean systolic pressure } \\
\text { - } \quad \text { Mean diastolic pressure } \\
\text { Prehospital intubation } \\
\text { Intubation within } 1 \text { month } \\
\text { Died within } 30 \text { days } \\
\text { Median ICU LOS } \\
\text { Median hospital LOS } \\
\text { Dyspnoea score }\end{array}$ & $\begin{array}{c}22(35.5 \%) \\
\\
8.5 \\
\\
\\
\\
1(2 \%) \\
3(5 \%) \\
7(11 \%) \\
8.2 \text { hours } \\
6 \text { days } \\
4.8\end{array}$ & $\begin{array}{c}19(31.7 \%) \\
\\
4.9 \\
\\
\\
\\
\\
2(3 \%) \\
6 \text { (10\%) } \\
8 \text { hours } \\
6 \text { days } \\
5.3\end{array}$ & $\begin{array}{l}0.52 \\
0.52 \\
0.27 \\
0.50 \\
0.47\end{array}$ \\
\hline $\begin{array}{l}\text { Hubble et al. }(2006)^{38} \\
\text { Non-CPAP=95 } \\
\text { CPAP=120 }\end{array}$ & $\begin{array}{l}\text { Pre-hospital time } \\
\text { Physiology changes } \\
\text { - Improvement in respiratory } \\
\text { rate } \\
\text { - Improvement in pulse rate } \\
\text { - Improvement in dyspnoea }\end{array}$ & $\begin{array}{l}30 \\
-1.81 \\
0.82 \\
-1.36\end{array}$ & $\begin{array}{l}32 \\
-4.55 \\
-4.77 \\
-2.11\end{array}$ & $\begin{array}{l}0.001 \\
0.013 \\
0.008\end{array}$ \\
\hline
\end{tabular}




\begin{tabular}{|c|c|c|c|c|}
\hline & $\begin{array}{l}\quad \text { score } \\
\text { Pre-hospital intubation } \\
\text { Intubation anytime } \\
\text { In-hospital mortality } \\
\text { Hospital LOS }\end{array}$ & $\begin{array}{c}7(7 \%) \\
25 \% \\
23 \% \\
8 \text { days }\end{array}$ & $\begin{array}{c}5(4 \%) \\
9 \% \\
5 \% \\
6 \text { days } \\
\end{array}$ & $\begin{array}{c}0.48 \\
\text { OR 4.0; } 95 \% \mathrm{Cl} 1.6 \text { to } 9.9 \\
\text { OR } 7.5 ; 95 \% \mathrm{Cl} 2.0 \text { to } 28.5 \\
0.76\end{array}$ \\
\hline $\begin{array}{l}\text { Thompson et al. } .^{14} \\
\text { Non-CPAP }=35 \\
\text { CPAP }=34\end{array}$ & $\begin{array}{l}\text { Scene time } \\
\text { Prehospital intubation } \\
\text { Prehospital to hospital discharge } \\
\text { intubation } \\
\text { Mortality } \\
\text { Number of critical care admissions } \\
\text { Median critical care LOS } \\
\text { Hospital LOS }\end{array}$ & $\begin{array}{l}21 \text { minutes } \\
9 \\
\text { In addition } 2 \text { pts } \\
\text { had attempted } \\
\text { intubation } \\
17(50 \%) \\
12(35 \%) \\
16(47) \\
3 \text { days } \\
9 \text { days }\end{array}$ & $\begin{array}{l}22 \text { minutes } \\
0 \\
7(20 \%) \\
5(14 \%) \\
13 \text { (37) } \\
6.5 \text { days } \\
7 \text { days }\end{array}$ & $\begin{array}{l}\text { Unadjusted OR } 0.25 ; 95 \% \mathrm{Cl} \\
0.09 \text { to } 0.73 ; \text { adjusted OR } \\
0.16 ; 95 \% \mathrm{Cl} 0.04 \text { to } 0.7 \\
\text { Unadjusted OR } 0.3 ; 95 \% \mathrm{Cl} \\
\quad 0.09 \text { to } 0.99\end{array}$ \\
\hline
\end{tabular}

*Pre-hospital time = arrival at scene to arrival at emergency department

bpm breaths per minute

$\mathrm{Cl} \quad$ Confidence Interval

DBP Diastolic Blood Pressure

LOS Length of Stay

OR Odds Ratios

SBP Systolic Blood Pressure

$\mathrm{SaO}_{2} \quad$ Arterial Oxygen Saturation

$\mathrm{SpO}_{2} \quad$ Peripheral Oxygen Saturation 